\title{
Relationship between duodenal bile acids and colorectal neoplasia
}

\author{
R J MOOREHEAD, G R CAMPBELL, J D DONALDSON, AND \\ $S$ T D McKELVEY
}

From the Department of Surgery, The Queen's University of Belfast, Belfast, Northern Ireland

SUMmARY To investigate a possible relationship between bile acids and colorectal neoplasia duodenal bile acids were analysed in 50 patients with colorectal adenomas and 14 with carcinoma. Using gas liquid and high performance liquid chromatography a small, but significant increase in the proportion of chenodeoxycholic acid was found in the bile of adenoma patients compared with controls (mean \% \pm SD $31 \cdot 0 \pm 10 \cdot 8,26 \cdot 4 \pm 8 \cdot 3, \mathrm{p}=0 \cdot 01$ ). The difference in the proportions of chenodeoxycholic acid correlated with increasing malignant potential of the adenomas as determined by increasing size, histological type, degree of dysplasia and number present. In carcinoma patients an increase in the proportion of chenodeoxycholic acid was also observed compared with controls (mean $\% \pm S D, 47 \cdot 2 \pm 9 \cdot 6,28 \cdot 0 \pm 4 \cdot 5, \mathrm{p}<0 \cdot 01$ ). The proportions of other bile acids in those with adenoma or carcinoma were normal.

Bile acids are believed to play a role in the aetiology of colorectal cancer,' and this theory is supported by reports of increased concentrations of bile acids in the faeces of those from countries with a high incidence of the disease. ${ }^{-h}$ It is further supported by reports of increased concentrations of faecal bile acids in those with colorectal adenomas or carcinomas when compared with healthy individuals from the same high risk community. ${ }^{7 x}$ Such studies together with a considerable amount of experimental evidence suggest a definite relationship between bile acids and the pathogenesis of large bowel cancer. ${ }^{\prime \prime \prime}$ Others finding no correlation between faecal bile acids and the presence or risk of colorectal cancer have raised some doubts over the proposed role of bile acids. ${ }^{11-1.3}$ The measurement of bile acids in faeces is a complex process and it is possible that methodological problems could account for some of these varied findings. ${ }^{1+}$ Two recent studies, although small, have been unable to confirm a relationship between increased concentrations of faecal bile acids and the presence of colorectal adenomas or carcinomas. ${ }^{15} 1 \mathrm{th}$ Both are critical of the methods used in earlier investigations and suggest that methodological prob-

Address for correspondence: Mr R J Moorehead, MD. FRCS, Department of Surgery. The Queen's University of Belfast. Institute of Clinical Science, Grosvenor Road. Belfast BT12 6BJ. Northern Ireland.

Received for publication 30 April 1987 lems may account for the different results. Others have stressed the need for standardising such methods before any valid comparisons can be made. ${ }^{17}$

Alternative means of determining the role of bile acids in the development of colonic cancer have been sought. In a study of colonic absorption of bile acids it was observed that those with adenomas had increased levels of secondary bile acids in duodenal bile. ${ }^{18}{ }^{19}$ Although only a small number of subjects were studied, the results suggest that duodenal bile analysis may give useful information on the proposed link between bile acids and colorectal adenomas or carcinomas.

The aim of the present study was to determine whether subjects with colorectal adenomas or carcinomas have abnormal duodenal bile acid profiles when compared with healthy controls.

\section{Methods}

PATIENTS

The adenoma group comprised 50 patients $(28$ men, 22 women). The mean \pm SD age of the group was $63.6 \pm 11.4$ years. After resection at colonoscopy the adenomas were classified as either tubular, tubulovillous or villous in type and the degree of dysplasia graded from none to mild, moderate, severe (carcinoma in situ) or malignant. The patients returned at a 
later date for duodenal bile sampling. None had undergone previous gastric or intestinal surgery. Three had previous cholecystectomy. In six the gall bladder was known to be normal and in 41 cases the condition of the gall bladder was unknown.

The control group comprised 50 healthy people being investigated for peptic ulceration and hiatus hernia. Their mean $\pm \mathrm{SD}$ age was $53 \cdot 4 \pm 16 \cdot 0$ years. In 32 cases the gall bladder was known to be normal and functioning as determined by ultrasound or cholecystography, and in 18 cases the condition of the gall bladder was unknown.

Fourteen patients (seven men, seven women) with previously resected carcinomas were studied. The mean $\pm S D$ age of the group was $69 \cdot 1 \pm 12 \cdot 5$ years. Eleven had rectal tumours, three had sigmoid tumours. The mean \pm SD time between surgical resection and bile sampling was $45 \cdot 2 \pm 36 \cdot 1$ months. Ten of the group were known to have normal gall bladders and in four cases the condition of the gall bladders, although present, was not known. All had normal liver function tests. One patient had had a previous partial gastrectomy for peptic ulceration. Age and sex matched controls were drawn from the same group from which the adenoma controls were obtained.

All patients and controls were well, on a normal diet and with a normal bowel habit. None were on drug therapy likely to affect bile acid metabolism or absorption.

After an overnight fast an intravenous injection of Pancreozymin (Boots) was given. An Olympus Q-10 endoscope was passed until its tip reached the ampulla of Vater. Residual juice was aspirated and discarded. When a good flow of bile was visualised it was collected and stored at $-60^{\circ} \mathrm{C}$ until later analysis using the techniques of gas liquid and high performance chromatography.

Gas liquid chromatography (GLC) analysis was carried out on the methylated, trimethylsilyl derivatives of the acids after enzymatic deconjugation..$^{212+2+}$ A Pye series 104 chromatograph, model 64 , equipped with a hydrogen flame detector, temperature programming unit and injection point heaters, with a Pye unicam PU4810 computing integrator for recording traces was used. Columns were packed with $1 \% \mathrm{Hi}$ Eff 8BP gas chrom Q 100/120 mesh (Field Analytical
Company Ltd). The carrier gas (nitrogen) and detector gas (hydrogen) flow rates were $650 \mathrm{ml} / \mathrm{min}$. The oven temperature was $220^{\circ} \mathrm{C}$.

The technique for high performance liquid chromatography (HPLC) analysis was based on methods described by Alme and Nystrom and Goto et al. ${ }^{25-27}$ A Waters model M45 pump, Waters UBondpak C18 column, Reodyne 1257 injection value, UVicord S Detector (LKB) and a Hewlett Packard 3390A integrator were used.

\section{Results}

Gas liquid chromatography analysis detected seven bile acids in duodenal bile: cholic acid (CA), an unidentified acid (XA), deoxycholic acid (DCA), chenodeoxycholic acid (CDCA), lithocholic acid (LCA), a second unidentified acid (YA) and ursodeoxycholic acid (UDCA) (Table 1).

There was a significant increase in the proportion of chenodeoxycholic acid present in the bile of adenoma patients compared with controls, $31 \cdot 0 \%$ : $26.4 \%, p=0.01$. The proportions of the other bile acids in the adenoma group did not differ from control values. There was a trend, however, for a decrease in the proportion of cholic acid present in the bile of the adenoma group, $46 \cdot 5 \%: 50 \cdot 9 \%(p=$ $0 \cdot 07)$.

When the adenomas were single, $2 \mathrm{~cm}$ or less in diameter, tubular in type or having either no or only mild dysplastic changes, the bile acid profiles were not different from those of the controls. When the adenomas were multiple, larger than $2 \mathrm{~cm}$, tubulovillous or villous in type, or having moderate to severe dysplastic changes, significant differences between the bile acid profiles of these subjects and the controls were observed (Table 2). In all of these subgroups the proportion of chenodeoxycholic acid present was increased and when moderate to severe degrees of dysplasia were present, a decrease in the proportion of cholic acid was present, $44 \cdot 1 \%: 51 \cdot 1 \%$, $p=0 \cdot 02$. The proportions of the other bile acids present in these subgroups was normal.

Carcinoma patients also had an increase in the proportion of chenodeoxycholic acid, $42 \cdot 2 \%: 28.0 \%$, $\mathrm{p}<0.01$ (Table 3 ). There was no difference between the proportions of the other bile acids present,

Table 1 Mean percentages $\pm S D$ of bile acids in adenoma group and controls

\begin{tabular}{|c|c|c|c|c|c|c|c|c|}
\hline$n=50$ & & $C A$ & $X A$ & $D C A$ & $C D C A$ & $L C A$ & $Y A$ & $U D C A$ \\
\hline Adenoma group & Mcan $\% \pm S D$ & $46 \cdot 5$ & $2 \cdot 4$ & $19 \cdot 4$ & $31 \cdot()$ & 0.2 & $0 \cdot 1$ & 0.5 \\
\hline \multirow[t]{2}{*}{ Control group } & Mcan $\% \pm \mathrm{SD}$ & $50 \cdot 9$ & 1.9 & $20 \cdot 5$ & $26 \cdot 4$ & $0 \cdot 2$ & $0 \cdot 0$ & 0.1 \\
\hline & & $13 \cdot()$ & $3 \cdot 2$ & $11 \cdot 5$ & $8 \cdot 3$ & $1 \cdot 1$ & $0 \cdot()$ & 0.4 \\
\hline
\end{tabular}


Table 2 Proportions of chenodeoxycholic acid in adenoma subgroups compared with controls

\begin{tabular}{|c|c|c|c|c|}
\hline \multirow[b]{2}{*}{ Malignant potential of adenomas } & \multirow{2}{*}{$\begin{array}{l}\text { Group } \\
\text { (n) }\end{array}$} & \multicolumn{2}{|c|}{ Mean \% $\% S D$ chenodeoxycholic acid } & \multirow[b]{2}{*}{ p value } \\
\hline & & Adenoma & Control & \\
\hline Size less than or equal to $2 \mathrm{~cm}$ & 31 & $31 \cdot 0 \pm 11 \cdot 3$ & $27 \cdot 0 \pm 7 \cdot 1$ & NS \\
\hline $\mathrm{Sizc}>2 \mathrm{~cm}$ & 19 & $31 \cdot 2 \pm 10 \cdot()$ & $25 \cdot 6 \pm 9-8$ & $<0 \cdot 05$ \\
\hline Tubular & 13 & $27 \cdot 1 \pm 10 \cdot 4$ & $26 \cdot 6 \pm 7 \cdot 0$ & \\
\hline Intermediate or villous & 35 & $32 \cdot 4 \pm 10 \cdot 6$ & $26 \cdot 4 \pm 8 \cdot 7$ & $\begin{array}{l}\text { NS } \\
0.016\end{array}$ \\
\hline Nonc or mild dysplasia & 22 & $27 \cdot 5 \pm 10 \cdot 0$ & $27 \cdot 3 \pm 6 \cdot 4$ & $\begin{array}{l}0.016 \\
\text { NS }\end{array}$ \\
\hline Moderate or severe dysplasia & 28 & $33 \cdot 8 \pm 10 \cdot 6$ & $25 \cdot 7 \pm 9 \cdot 4$ & \\
\hline Number $=1$ & 29 & $29 \cdot 1 \pm 11 \cdot 3$ & $26 \cdot 7 \pm 8 \cdot 8$ & $\begin{array}{l}0.0048 \\
\text { NS }\end{array}$ \\
\hline Number equal to or greater than 2 & 21 & $33 \cdot 8 \pm 9 \cdot 3$ & $26 \cdot 1 \pm 7 \cdot 4$ & $<0.01$ \\
\hline
\end{tabular}

Table 3 Mean percentages $\pm S D$ of bile acids present in carcinoma patients and controls

\begin{tabular}{|c|c|c|c|c|c|c|c|c|}
\hline$n=14$ & & $C A$ & $X A$ & $D C A$ & $C D C A$ & $L C A$ & $Y A$ & $U D C A$ \\
\hline \multirow[t]{2}{*}{ Cancer group } & Mcan $\% \pm S D$ & $36 \cdot 5$ & $4 \cdot 9$ & $16 \cdot 0$ & $42 \cdot 2$ & 0.0 & $0 \cdot 0$ & 0.4 \\
\hline & & $9 \cdot 9$ & $2 \cdot 8$ & $8 \cdot 7$ & $9 \cdot 6$ & 0.0 & $0 \cdot()$ & 0.8 \\
\hline \multirow[t]{2}{*}{ Control group } & Mcan $\% \pm S D$ & $47 \cdot 5$ & $2 \cdot 7$ & $21 \cdot 6$ & $28 \cdot 0$ & 0.1 & $0 \cdot()$ & $0 \cdot 2$ \\
\hline & & $11 \cdot 8$ & $3 \cdot 3$ & $10 \cdot 9$ & $4 \cdot 5$ & $0 \cdot 2$ & $0 \cdot()$ & $0 \cdot 5$ \\
\hline
\end{tabular}

though again there was a trend for lower levels of cholic acid in the carcinoma group.

High performance liquid chromatography identified eight bile acids in 38 of the adenoma patients. These were the glycine and taurine conjugates of cholic (G+TCA), deoxycholic (G+TDCA), chenodeoxycholic (G+TCDCA) and lithocholic acids (G+TLCA). Ursodeoxycholic acid was not identified using HPLC. Up to five unidentified peaks were observed in the samples from adenoma patients and controls.

The tauro and glyco fractions of each bile acid in the adenoma group were compared with the controls (Tables 4 and 5). The increase in the proportions of

Table 4 Mean percentages $\pm S D$ of combined tauro and glycoconjugates in adenoma and control groups

\begin{tabular}{lllrl}
\hline$n=50$ & & $T+G C A$ & $T+G C D C A$ & $T+G D C A$ \\
\hline Adenoma & Mcan \% & $41 \cdot 8$ & $37 \cdot 7$ & $19 \cdot 2$ \\
group & \pm SD & $11 \cdot 3$ & 8.9 & $11 \cdot 0$ \\
Control & Mean \% & 43.5 & 31.9 & 22.5 \\
group & \pm SD & $11 \cdot 5$ & $9 \cdot 7$ & 13.9 \\
\hline
\end{tabular}

chenodeoxycholic acid in the adenoma group was confirmed, $37 \cdot 7 \%: 31.9 \%, p=0.04$, and this was mainly in the glycine fraction $(26.3 \%: 21.9 \%$, $p=0 \cdot 05$ ). As with GLC analysis there was no difference between the proportions of the other bile acids present.

\section{Discussion}

We have shown that patients with colorectal adenomas have abnormal duodenal bile acid profiles when compared with matched controls. The principal difference between the two groups was a small but significant increase in the proportion of chenodeoxycholic acid in the bile of those with adenomas which correlated with increasing malignant potential as determined by increasing size, number, histological type and the degree of dysplasia present. ${ }^{2 *-31}$ This was matched by a decrease in the proportion of cholic acid present in the adenoma group although this did not reach statistical significance. Similar differences were found in the bile of those with previous carcinomas and had a larger number of such patients been studied the reciprocal fall in the proportion of

Table 5 Mean percentages $\pm S D$ of the conjugates of each bile acid present in the adenoma group and controls

\begin{tabular}{|c|c|c|c|c|c|c|c|}
\hline$n=50$ & & $T C A$ & $T C D C A$ & $T D C A$ & $G C A$ & $G C D C A$ & $G D C A$ \\
\hline Adenoma group & Mean $\% \pm \mathrm{SD}$ & $\begin{array}{c}12 \cdot 8 \\
6 \cdot 2\end{array}$ & $\begin{array}{r}11.4 \\
7.9\end{array}$ & $\begin{array}{l}2 \cdot 6 \\
5 \cdot 8\end{array}$ & $\begin{array}{r}28.9 \\
9.8\end{array}$ & $\begin{array}{r}26.3 \\
9.9\end{array}$ & $\begin{array}{l}16 \cdot 6 \\
10 \cdot 4\end{array}$ \\
\hline Control group & Mcan $\% \pm S D$ & $\begin{array}{r}12 \cdot 0 \\
6 \cdot 8\end{array}$ & $\begin{array}{r}10 \cdot() \\
5.9\end{array}$ & $\begin{array}{l}3 \cdot 1 \\
2 \cdot 5\end{array}$ & $\begin{array}{r}31 \cdot 5 \\
9.1\end{array}$ & $\begin{array}{r}21.9 \\
8 .(9\end{array}$ & $\begin{array}{l}19 \cdot 4 \\
12 \cdot 7\end{array}$ \\
\hline
\end{tabular}


cholic acid may have reached statistical significance.

These results support those recently reported by Owen et al $^{\text {: }}$ who studied the major bacterial metabolites of chenodeoxycholic acid and cholic acid. They observed an increased ratio of lithocholic to deoxycholic acid in the faeces of some adenoma and cancer patients compared with controls and this is in keeping with the increased concentrations of chenodeoxycholic acid seen in the bile of our tumour bearing patients.

The results of this study appear to contradict those of Van der Werf et a $l^{1 / 11}$ who were the first to report abnormalities in duodenal bile acids of those with adenomas. They reported an increase in the proportion of secondary bile acids, principally deoxycholic acid, at the expense of a decrease in cholic acid. While the fall in the level of cholic acid would be in agreement with our findings, we could not confirm the finding of increased concentrations of deoxycholic acid in these patients. In their original study group of 11 adenoma patients, three had undergone previous cholecystectomy. Such a group are known to have increased concentrations of secondary bile acids ${ }^{32-35}$ and this may have influenced their results.

The differences in this study in the proportions of chenodeoxycholic acid between adenoma patients and controls, although significant, were small and raises the question whether the methods of bile acid analysis were sufficiently accurate and reliable to show such small differences. Studies on reproducibility showed recovery rates of bile acids that were high and consistent. Using high performance liquid chromatography (HPLC) increased proportions of chenodeoxycholic acid were confirmed in adenoma patients. This gives confidence in the accuracy of the laboratory methods used.

The use of HPLC permitted the determination of glycine and taurine conjugates of the bile acids. It revealed an increase in the glycine fraction and not the taurine conjugate. Glycine conjugates normally exceed those of taurine ${ }^{3 /}$ but the selective increase in the type of conjugation observed in this study remains unexplained.

Does removal of the adenoma or carcinoma affect the bile acid profiles? In the majority of cases the duodenal bile samples were obtained some time after polypectomy or resection of the carcinomas. The differences observed have persisted despite removal of the tumours. The correlation with increasing malignant potential suggests a causal relationship and may also have a bearing on the development of metachronous tumours.

Gall bladder function has a major influence on bile acid metabolism. Where the state of the gall bladder is unknown there is the possibility of cholelithiasis or non-function. With the majority of the controls having normal gall bladders and the majority of the adenoma patients having undetermined gall bladder status and function, a possible, although unavoidable, source of error may have existed.

Variations in bile acid metabolism with age are known to occur and include less effective absorption of cholic acid in the elderly." To allow for these differences we tried to match for age as closely as possible but on average our controls were approximately 10 years younger than the adenoma patients. An increase in the proportion of secondary bile acids in duodenal bile was not observed, suggesting that failure to achieve good age matching did not affect the outcome of the study.

Some unknown peaks were identified on the chromatographs obtained using both GLC and HPLC, which may have been unknown bile acids or simply artefacts produced during the process of analysis. Strong alkaline hydrolysis of sulphate esters, as commonly occurs during bile acid analysis, can result in a number of degradation products producing abnormal peaks. ${ }^{\text {* }}$ While this might explain these findings, it seems unlikely as the hydrolysis used in our GLC analysis is a weak one. These unknown peaks may therefore represent bile acids and the unknown peaks obtained with HPLC may represent their glycine and taurine conjugates. As they appeared equally in patients and controls they are probably irrelevant in the context of colorectal neoplasia.

Until the possible role of chenodeoxycholic acid and its metabolites in the pathogenesis of colorectal adenomas and carcinomas is defined, it is reasonable to suggest caution in the use of such a bile acid in the medical treatment of cholelithiasis. This cautionary note is shared by Sachatello et al " and Williamson and Rainey."

The results of this study pose more questions than they answer. The possible abnormalities in bile acid metabolism of those with adenomas and carcinomas suggests a need for further studies to investigate terminal ileal function, colonic absorption of bile acids and bile acid pool sizes in these individuals.

In conclusion, by showing differences between the bile acid profiles of patients with colorectal adenomas or carcinomas and matched controls, further support for the concept that bile acids have a role to play in the development of large bowel tumours is shown.

\section{References}

1 Aries V, Crowther JS, Drasar BS, Hill MJ, Williams REO. Bacteria and the aetiology of cancer of the large bowel. Gut 1969; 10: 334-5.

2 Hill MJ, Crowther JS, Drasar BS, Hawksworth G, Aries $\mathrm{V}$, Williams REO. Bacteria and aetiology of cancer of large bowel. Lancet 1971; i: 95-100). 
3 Reddy BS, Wynder EL. Large bowel carcinogenesis: faecal constituents of populations with diverse incidence rates of colon cancer. J Natl Cancer Inst 1973; 50: 1437-42.

4 Reddy BS, Hedges AR, Laakso K, Wynder EL. Metabolic epidemiology of large bowel cancer. Fecal bulk and constitutents of high risk North American and low risk Finnish population. Cancer 1978; 42: 2832-8.

5 Mower HF, Ray RM, Shoff R, et al. Fecal bile acids in two Japanese populations with different colon cancer risks. Cancer Res 1979; 39: 328-31.

6 Domellof L, Darby L, Hanson D, Mathews L, Simi B, Reddy BS. Fecal sterols and bacterial beta-glucuronidase activity: a preliminary metabolic epidemiology study of healthy volunteers from Urmea, Sweden and Metropolitan New York. Nutr Cancer 1982; 4: 120-7.

7 Hill MJ, Drasar BS, Williams REO, et al. Faecal bile acids and clostridia in patients with cancer of the large bowel. Lancet 1975; i: 535-39.

8 Reddy BS, Wynder EL. Metabolic epidemiology of colon cancer. Fecal bile acids and neutral sterols in colon cancer patients and patients with adenomatous polyps. Cancer 1977; 39: 2533-9.

9 Reddy BS, Narisawa T, Maronpot R, Weisburger JH, Wynder EL. Animal models for the study of dietary factors and cancer of the large bowel. Cancer Res 1975; 35: 3421-6.

10 Reddy BS, Watanabe K, Weisburger JH, Wynder EL. Promoting effect of bile acids in colon carcinogenesis in germ-free and conventional F344 rats. Cancer Res 1977; 37: 3238-42.

11 Moskovitz M, White C, Barnett RN, et al. Diet fecal bile acids and neutral sterols in carcinoma of the colon. Dig Dis Sci 1979; 24: 746-51.

12 Mudd DG, McKelvey ST, Norwood W, Elmore DT, Roy AD. Faecal bile acid concentration of patients with carcinoma or increased risk of carcinoma in the large bowel. Gut 1980; 21: 587-90.

13 Murray WR, Backwood A, Trotter JM, Calman KC, MacKay C. Faecal bile acids and clostridia in the aetiology of colorectal cancer. Br J Cancer 1980; 41: 923-8.

14 Setchell KD, Gilbert JM, Lawson AM. Fat and cancer [Letter]. Br Med J 1983; 286: 1750.

15 Hikasa Y, Tanida N, Ohno T, Shimoyama T. Faecal bile acid profiles in patients with large bowel cancer in Japan. Gut 1984; 25: 833-8.

16 Tanida N, Hikasa Y, Shimoyama T, Setchell KDR. Comparison of faecal bile acid profiles between patients with adenomatous polyps of the large bowel and healthy subjects in Japan. Gut 1984; 25: 824-32.

17 Vahouny GV, Kay R. Working Group III: lipid metabolites and intestinal flora. Summary, conclusion and recommendations Cancer Res 1981; 41: 3781-2.

18 Van der Werf SDJ, Nagengast FM, Van Berge Henegouwen GP, Huijbregts AWM, Van Tongeren JHM. Colonic absorption of secondary bile acids in patients with adenomatous polyps and in matched controls. Lancet 1982; 1: 759-62.

19 Van der Werf SDJ, Nagengast FM, Van Berge Henegouwen GP, Huijbregts AW, Van Tongeren JHM.
Intracolonic environment and the presence of colonic adenomas in man. Gut 1983; 24: 876-80.

20 Klaassen CD. Gas liquid chromatographic determination of bile acids in bile. Clin Chim Acta 1971; 35: 225-9.

21 Henegouwen GP, Van Berge, Ruben A, Brandt KH. Quantitative analysis of bile acids in serum and bile using gas liquid chromatography. Clin Chim Acta 1974; 54: 249-61.

22 Taylor $\mathrm{W}$. The bile acid composition of rabbit, cat gallbladder bile. J Steroid Biochem 1977; 8: 1077-84.

23 Taylor W, Ellis WR, Bell GD. The effect of cholesterol feeding on gallbladder bile acids of the rabbit. Biochem $J$ 1981; 198: 639-43.

24 Street JM, Trafford DJH, Makin HLJ. The quantitative estimation of bile acids and their conjugates in human biological fluids. J Lipid Res 1983; 24: 491-511.

25 Alme B, Nystrom E. Preparation of lipophilic anion exchanges from chlorohydroxypropylated sephadex and cellulose. J Chromatogr 1971; 59: 45-52.

26 Goto J, Hasegawa M, Kato H, Nambara T. A new method for simultaneous determination of bile acids in human bile without hydrolysis. Clin Chim Acta 1978; 87: 141-7.

27 Goto J, Kato H, Saruta Y, Nambara T. Separation and determination of bile acids in human bile by high performance liquid chromatography. Chromatography 1980; 3: 991-1103.

28 Day DW, Morson BC. The adenoma-carcinoma sequence. In: Morson $\mathrm{BC}$, ed. The pathogenesis of colorectal cancer. London: Saunders, 1978: 58-71.

29 Morson BC. Evolution of cancer of the colon and rectum. Cancer 1974; 34: 845-49.

30 Muto T, Bussey HJR, Morson BC. The evolution of cancer of the colon and rectum. Cancer 1975; 36: 2251-70.

31 Owen RW, Henly PJ, Day D, Thompson MH, Hill MJ. Faecal steroids and colorectal cancer: bile acid profiles in low and high risk groups. Br J Surg 1985; 72: suppl: S137.

32 Almond HR, Vlachevic ZR, Bell CC, Gregory DH, Swell L. Bile acid pool kinetics and biliary lipid composition before and after cholecystectomy. $N$ Engl J Med 1973; 289: 1213-6.

33 Malagelada JR, Go VLW, Summerskill WHJ, Gamble WS. Bile acid secretion and biliary bile acid composition altered by cholecystectomy. Am J Digest Dis 1973; 18: 455-9.

34 Pomare EW, Heaton KW. The effect of cholecystectomy on bile salt metabolism. Gut 1973; 14: 753-62.

35 Hepner GW, Hofmann AF, Malagelada JR, Szczepanik PA, Klein PD. Increased bacterial degradation of bile acids in cholecystectomised patients. Gastroenterology 1974; 16: 556-64.

36 Low-Beer TS. The physiology of enterohepatic circulation of bile salts. In: Proceedings of the first international symposium on bile acids in hepatobiliary and gastrointestinal diseases. Oxford: IRL Press, 1984; 1-8.

37 Van der Werf SD, Huijbregts AW, Lamers HL, Van Berge Henegouwen GP, Van Tongeren JH. Age dependent differences in human bile acid metabolism and 7-alpha-dehyproxylation. Eur J Clin Invest 1981; 11 : 425-31. 
38 Palmer RH, Bolt MG. Bile acid sulfates. Synthesis of lithocholic acid sulfates and their identification in human bile. J Lipid Res 1971; 12: 671-9.

39 Sachatello CR, Hedgecock H Jr, Armstrong A. What can experimental colorectal cancer tell us about colorectal cancer in man? Dis Colon Rectum 1980; 23: 80-5.

40 Williamson RCN, Rainey JB. The relationship between intestinal hyperplasia and carcinogenesis. Scand $J$ Gastroenterol 1984; 19: 57-76. 